\title{
MENINGKATKAN PENGETAHUAN MENGENAI PEMBERIAN ASI EKSLUSIF DAN MANAJEMEN LAKTASI MELALUI PENYULUHAN PADA IBU
}

\author{
https://doi.org/10.33024/jkpm.v4i6.4512
}

\begin{abstract}
Rudi Haryanto ${ }^{1 *}$, Febi Ratnasari ${ }^{2}$, Eka Puji Hastuti ${ }^{1}$, Liana Oktariani ${ }^{1}$, Osrika Hotnasari Sitompul ${ }^{1}$, Nurseha ${ }^{1}$, Rotua Nurmala Gurning ${ }^{1}$, Siska Karmelia ${ }^{1}$, Yudi Sulistyo ${ }^{1}$, Ola Filianata ${ }^{1}$, Diannita Tri Lestari ${ }^{1}$, Puspita Ayu Marhaeni ${ }^{1}$, Rafika Ulandari ${ }^{1}$

${ }^{1}$ Mahasiswa Profesi Ners STIKES Yatsi Tangerang ${ }^{2}$ Dosen STIKES Yatsi Tangerang
\end{abstract}

Disubmit: 13 Juni 2021 Diterima: 23 Juni 2021 Diterbitkan: 01 Desember 2021

Email Korespondensi: rudi18haryanto@gmail.com

\begin{abstract}
ABSTRAK
Bayi baru lahir perlu mendapat perawatan yang optimal sejak dini, termasuk pemberian makanan yang ideal. Air Susu Ibu (ASI) eksklusif adalah sumber nutrisi terbaik pada bayi. Pemberian ASI ekslusif diketahui dapat mencegah terjadinya stunting pada anak. Terdapat berbagai kendala yang muncul dalam upaya pemberian ASI ekslusif seperti kurangnya tingkat pengetahuan ibu mengenai manajemen laktasi dan teknik pemberian ASI ekslusif. Tujuan kegiatan ini adalah dengan memberikan penyuluhan secara daring tentang manajemen laktasi dan teknik pemberian ASI ekslusif dengan baik dan benar diharapkan dapat mengurangi resiko terjadinya stunting pada anak. Metode penyuluhan menggunakan presentasi power point mengenai manajemen laktasi dan manfaat ASI ekslusif serta demonstrasi cara menyusui yang benar dan teknik pijat oksitosin melalui aplikasi Zoom Meeting. Setelah dilakukan penyuluhan didapatkan peningkatan pengetahuan ibu-ibu tentang teknik menyusui dengan baik dan benar cara meningkatkan produksi ASI.
\end{abstract}

Kata Kunci: ASI Ekslusif, manajemen laktasi, penyuluhan

\section{ABSTRACT}

Newborns need to receive optimal care from an early age, including ideal feeding. Mothers' own milk is the best source of nutrition for nearly all infants. Exclusive breastfeeding can prevent stunting in children. There are various obstacles of that, such as the lack of knowledge of mothers about lactation management and exclusive breastfeeding techniques. This activity aims to provide online counseling about lactation management and the best breastfeeding techniques, which is expected to reduce the risk of stunting in children. A power point presentation of lactation management and the benefits of Mothers' own milk also the demonstration of the breastfeeding and oxytocin massage techniques were done through the Zoom Meeting application. After counseling, there was an increase in the knowledge of the mothers about exclusive breastfeeding techniques and how to increase Mothers' own milk.

Keywords: Exclusive breastfeeding, lactation management, counseling 


\section{PENDAHULUAN}

Secara global, sekitar 149 juta anak balita menderita stunting. Anakanak ini memulai hidup mereka dengan kerugian yang nyata: mereka menghadapi kesulitan belajar di sekolah, berpenghasilan lebih rendah sebagai orang dewasa, dan menghadapi hambatan untuk berpartisipasi dalam komunitas mereka. Pada Tahun 2018, lebih dari setengah dari semua anak di bawah 5 tahun yang mengalami stunting tinggal di Asia dan lebih dari sepertiganya tinggal di Afrika (WHO, 2019). Berdasarkan hasil survey Status Gizi Balita pada 2019, prevalensi stunting Indonesia tercatat sebesar 27,67 persen atau masih lebih tinggi dari standar yang ditetapkan oleh WHO yang tak boleh melebihi 20 persen (Kementerian Kesehatan RI, 2019).

Pemberian ASI ekslusif diketahui dapat mencegah terjadinya stunting pada anak (Sampe, Toban, \& Madi, 2020). Bayi baru lahir perlu mendapat perawatan yang optimal sejak dini, termasuk pemberian makanan yang ideal. Air Susu Ibu sumber nutrisi terbaik bagi bayi. ASI mengandung berbagai agen bioaktif yang membantu fungsi saluran pencernaan dan sistem kekebalan tubuh, serta dalam perkembangan otak (Martin, Ling, \& Blackburn, 2016). Secara nasional, cakupan bayi mendapat ASI eksklusif tahun 2019 yaitu sebesar 67,74\% telah melampaui target yaitu sebesar 50\%. Namun, masih terdapat empat provinsi yang belum mencapai target Renstra tahun 2019, yaitu Gorontalo, Maluku, Papua, dan Papua Barat. Untuk Propinsi Banten, cakupan pemberian ASI ekslusif baru mencapai 53,96\% atau masih di bawah rata-rata nasional (Kementerian Kesehatan RI, 2020).

Terdapat berbagai hambatan dalam praktik pemberian ASI ekslusif. Rasa kurang yakin akan kemampuan ibu dalam memberikan ASI eksklusif karena pengaruh keluarga dan budaya di masyarakat dan kurangnya dukungan dari tempat kerja membuat ibu tidak percaya diri dalam memberikan ASI ekslusif (Agustina, Prabandari, \& Sudargo, 2020).

Berdasarkan studi oleh Novitasari, Mawati, \& Rachmania (2019) menunjukkan bahwa ibu yang berpengetahuan baik cederung memberikan ASI eksklusif dan ibu yang berpengetahuan kurang cenderung tidak memberikan ASI eksklusif. Hal ini senada dengan studi dari Anggraini, Sari, \& Utami (2020) dan Mustafa \& Ibrahim (2019) yang menunjukkan bahwa ibu yang memiliki tingkat pengetahuan kurang, cenderung tidak memberikan ASI eksklusif. Lebih lanjut, Risnayati, Sudirman, \& Rosnawati (2018) menunjukkan ibu yang memiliki sikap positif cenderung memberikan ASI eksklusif dan ibu yang memiliki sikap negatif cenderung tidak memberikan ASI eksklusif.

Dengan memberikan penyuluhan mengenai pemberian ASI ekslusif pada bayi, diharapkan dapat meningkatkan pengetahuan dan pemahaman orang tua mengenai manfaat ASI, manajemen laktasi, dan teknik-teknik pendukung selama fase menyusui, sehingga dapat meningkatkan cakupan pemberian ASI ekslusif dan mendorong keberhasilan ibu agar dapat berhasil menyusui hingga bayi berusia dua tahun.

\section{MASALAH}

Masih rendahnya cakupan pemberian ASI ekslusif di Propinsi Banten serta masih kurangnya tingkat pengetahuan mengenai ASI ekslusif dan manajemen laktasi pada orangtua/ keluarga yang merupakan pasien-pasien kelolaan mahasiswa praktik profesi ners STIkes Yatsi Tangerang, merupakan salah satu alasan dilakukannya penyuluhan tentang pemberian ASI ekslusif dan manajemen laktasi. 


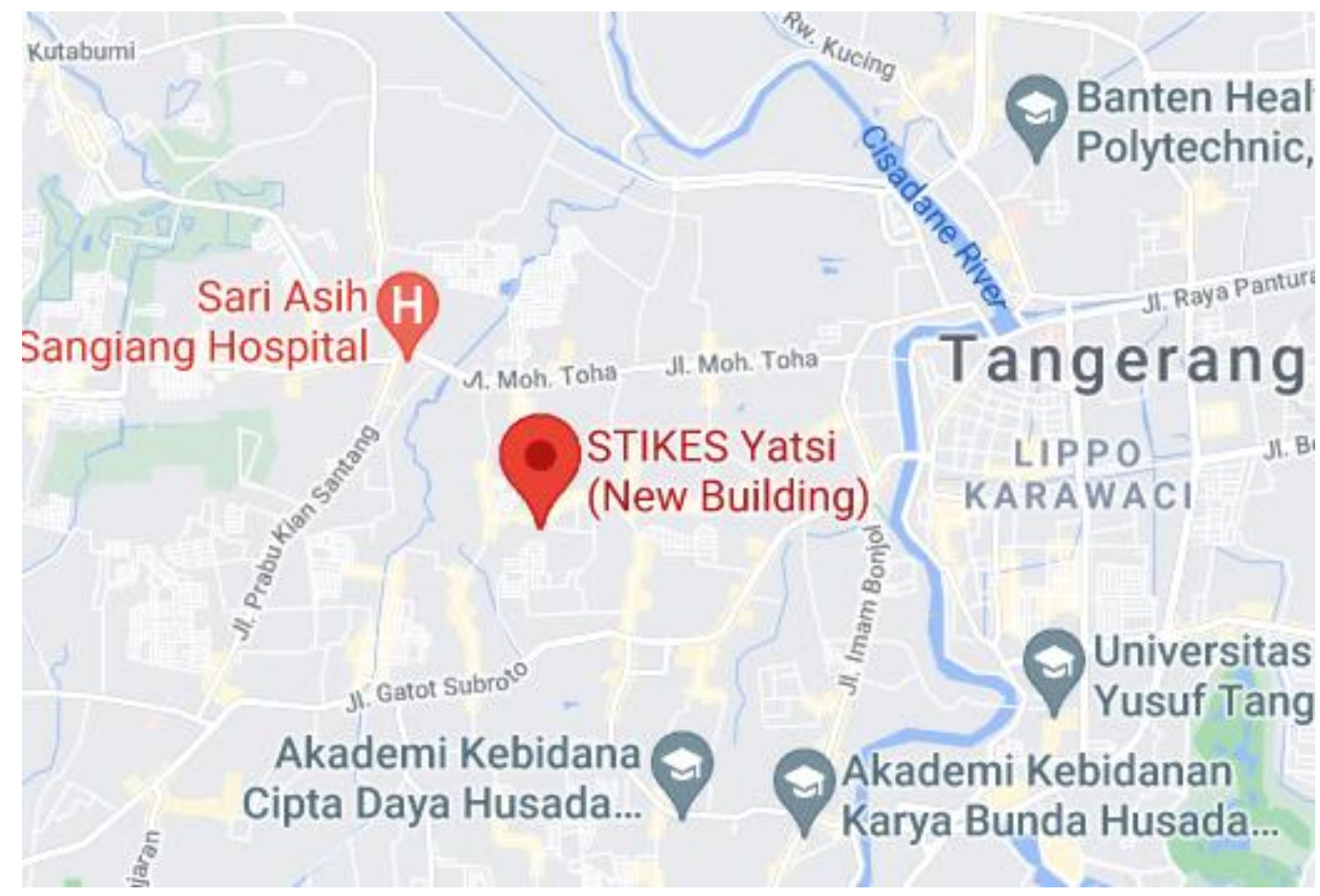

Gambar 2.1 Maps lokasi acara

\section{METODE}

a. Tahap persiapan

Tahap persiapan kegiatan ini dimulai dari pembuatan proposal kegiatan, materi penyuluhan dibuat secara singkat padat dan jelas dengan meminimalkan tulisan dan memberi gambar dalam power point hal tersebut untuk menarik perhatian sehingga memudahkan ibu untuk memahami materi, pembuatan link media dengan Zoom Meeting, mengingatkan kembali pada peserta untuk mengikuti acara.

b. Tahap pelaksanaan

Setelah semua peserta lengkap memasuki Zoom Meeting, ketua kelompok membuka acara dan dilanjutkan dengan presentasi secara jelas oleh narasumber serta dilanjutkan demonstrasi teknik menyusui yang baik dan benar, serta demonstrasi cara meningkatkan produksi ASI melalui teknik pijat oksitosin

c. Evaluasi

1) Struktur

Kegiatan diikuti oleh 100 orang ibu dan calon ibu, peserta mengikuti kegiatan melalui Zoom Meeting sesuai dengan rencana yang dibuat. Kegiatan penyuluhan dilakukan dengan lancar dan materi yang

2) Proses disampaikan dapat dipahami oleh peserta.

Pelaksanaan kegiatan dimulai dari pukul $15.00 \mathrm{~s} / \mathrm{d}$ 16.30 WIB sesuai dengan jadwal yang telah dibuat. 


\section{HASIL DAN PEMBAHASAN}

Menimbang kondisi pandemi dan masih berlakunya Pemberlakukan Pembatasan Kegiatan Masyarakat (PPKM) berskala Mikro di wilayah Tangerang Raya, maka kegiatan penyuluhan dilaksanakan di rumah masing-masing responden pada tanggal 11 Juni 2021 pukul 15.00 s/d 16.30 WIB dengan jumlah peserta 100 orang ibu dan calon ibu.

Tabel 4.1

Data responden berdasarkan usia

\begin{tabular}{lllc}
\hline No & usia & n & presentasi persen \\
\hline 1 & $20-25$ & 15 & $15 \%$ \\
\hline 2 & $25-30$ & 40 & $40 \%$ \\
\hline 3 & $30-35$ & 30 & $30 \%$ \\
\hline 4 & $35-40$ & 15 & $15 \%$ \\
\hline & Jumlah & 100 & $100 \%$ \\
\hline
\end{tabular}

Tabel 4.1 menunjukkan presentasi responden berdasarkan kelompok umur di dapatkan usia $20-25$ th sebanyak 15 orang (15\%), usia $25-30$ th sebanyak 40 orang( $40 \%)$, usia $30-35^{\text {th }}$ sebanyak 30 orang(30\%) dan usia $35-40$ orang sebanyak 15 orang $(15 \%)$.

Tabel 4.2

Data responden berdasarkan tingkat pendidikan

\begin{tabular}{cccc}
\hline No & Tingkat pendidikan & $\mathbf{n}$ & Presentase \\
\hline 1 & Sarjana & 65 & $65 \%$ \\
\hline 2 & SMA & 25 & $25 \%$ \\
\hline 3 & SMP & 10 & $10 \%$ \\
\hline & Jumlah & $\mathrm{N}=100$ & $100 \%$ \\
\hline
\end{tabular}

Dari tabel 4.2 menunjukan presentasi responden berdasarkan tingkat pendidikan didapatkan hasil bahwa 65 orang (65\%) sarjana, 25 orang (25\%) SMA dan 10 orang (10\%) berpendidikan SMP.

Tabel 4.3

Data responden berdasarkan jumlah anak

\begin{tabular}{cccc}
\hline No & Jumlah anak & $\mathbf{N}$ & Presentase \\
\hline 1 & $>2$ & 17 & $17 \%$ \\
\hline 2 & 1 & 35 & $35 \%$ \\
\hline 3 & Belum punya & 48 & $48 \%$ \\
\hline & Jumlah & $\mathrm{N}=100$ & $100 \%$ \\
\hline
\end{tabular}

Dari tabel 4.3 menunjukan tentang jumlah anak yang telah dimiliki oleh responden adalah 17 orang (17\%) telah mempunyai anak lebih 2, 35 orang(35\%) telah mempunyai 1 orang anak dan 48 orang (48\%) belum mempunyai anak. 
Tabel 4.4

Data responden berdasarkan pengetahuan ibu tentang teknik menyusui bayi dengan benar sebelum penyuluhan

\begin{tabular}{cccc}
\hline No & Teknik menyusui & N & Presentase \\
\hline 1 & Baik & 48 & $48 \%$ \\
\hline 2 & Cukup & 30 & $30 \%$ \\
\hline 3 & Kurang & 22 & $22 \%$ \\
\hline & Jumlah & $\mathrm{N}=100$ & $100 \%$ \\
\hline
\end{tabular}

Dari tabel 4.4 menunjukan tentang tingkat pemahaman teknik menyusui dengan benar yaitu sebanyak 48 responden (48\%) telah memahami dengan baik teknik menyusui yang benar, 30 responden (30\%) kurang memahami teknik menyusui dengan benar dan sebanyak 22 responden (22\%) kurang memahami teknik menyusui dengan benar.

Tabel 4.5

Data responden berdasarkan pengetahuan ibu cara meningkatkan produksi ASI sebelum penyuluhan

\begin{tabular}{cccc}
\hline No & $\begin{array}{c}\text { Meningkatkan } \\
\text { produksi ASI }\end{array}$ & N & Presentase \\
\hline 1 & Baik & 50 & $50 \%$ \\
\hline 2 & Cukup & 30 & $30 \%$ \\
\hline 3 & Kurang & 20 & $20 \%$ \\
\hline & Jumlah & $\mathrm{N}=100$ & $100 \%$ \\
\hline
\end{tabular}

Dari tabel 4.5 menunjukan tentang tingkat pengetahuan ibu mengenai cara meningkatkan produksi ASI yaitu sebanyak 50 responden (50\%) telah mengetahui cara meningkatkan produksi ASI, 30 responden (30\%) cukup mengetahui dan 20 responden $(20 \%)$ kurang mengetahui cara meningkatkan produksi ASI.

Setelah dilakukan penyuluhan tentang management pemberian ASI ekslusif pada bayi, praktek teknik menyusui dengan benar serta pimijatan oksitoksin untuk meningkatkan produksi ASI sehingga didapatkan peningkatan pengetahuan ibu.

Tabel 4.6

Data responden berdasarkan pengetahuan ibu tentang teknik menyusui bayi dengan benar sesudah penyuluhan

\begin{tabular}{cccc}
\hline No & Teknik menyusui & N & Presentase \\
\hline 1 & Baik & 80 & $80 \%$ \\
\hline 2 & Cukup & 20 & $20 \%$ \\
\hline & Jumlah & $\mathrm{N}=100$ & $100 \%$ \\
\hline
\end{tabular}

Dari tabel 4.6 menunjukan tentang tingkat pemahaman teknik menyusui dengan benar setelah diberikan penyuluhan adalah 80 responden $(80 \%)$ telah memahami teknik menyusui dengan benar, 20 responden (20\%) cukup memahami teknik menyusui dengan benar. 
Tabel 4.7

Data responden berdasarkan pengetahuan ibu cara meningkatkan produksi ASI setelah penyuluhan

\begin{tabular}{cccc}
\hline No & $\begin{array}{c}\text { Meningkatkan } \\
\text { produksi ASI }\end{array}$ & $\mathbf{N}$ & Presentase \\
\hline 1 & Baik & 90 & $90 \%$ \\
\hline 2 & Cukup & 10 & $10 \%$ \\
\hline 3 & Kurang & - & - \\
\hline & Jumlah & $\mathrm{N}=100$ & $100 \%$ \\
\hline
\end{tabular}

Dari tabel 4.7 menunjukan tingkat pengetahuan ibu cara meningkatkan produksi ASI setelah pengetahuan adalah 90 responden sudah mengetahui cara meningkatkan produksi ASI dan 10 responden cukup mengetahui tentang cara meningkatkan produksi ASI.

Kegiatan evaluasi tersebut dilakukan dengan memberikan pertanyaan melalui google form yang diisi oleh responden. Evaluasi tersebut dilakukan untuk mengetahui tingkat pemahaman ibu tentang teknik menyusui dengan benar dan cara meningkatkan produksi ASI dengan teknik pijat oksitoksin.
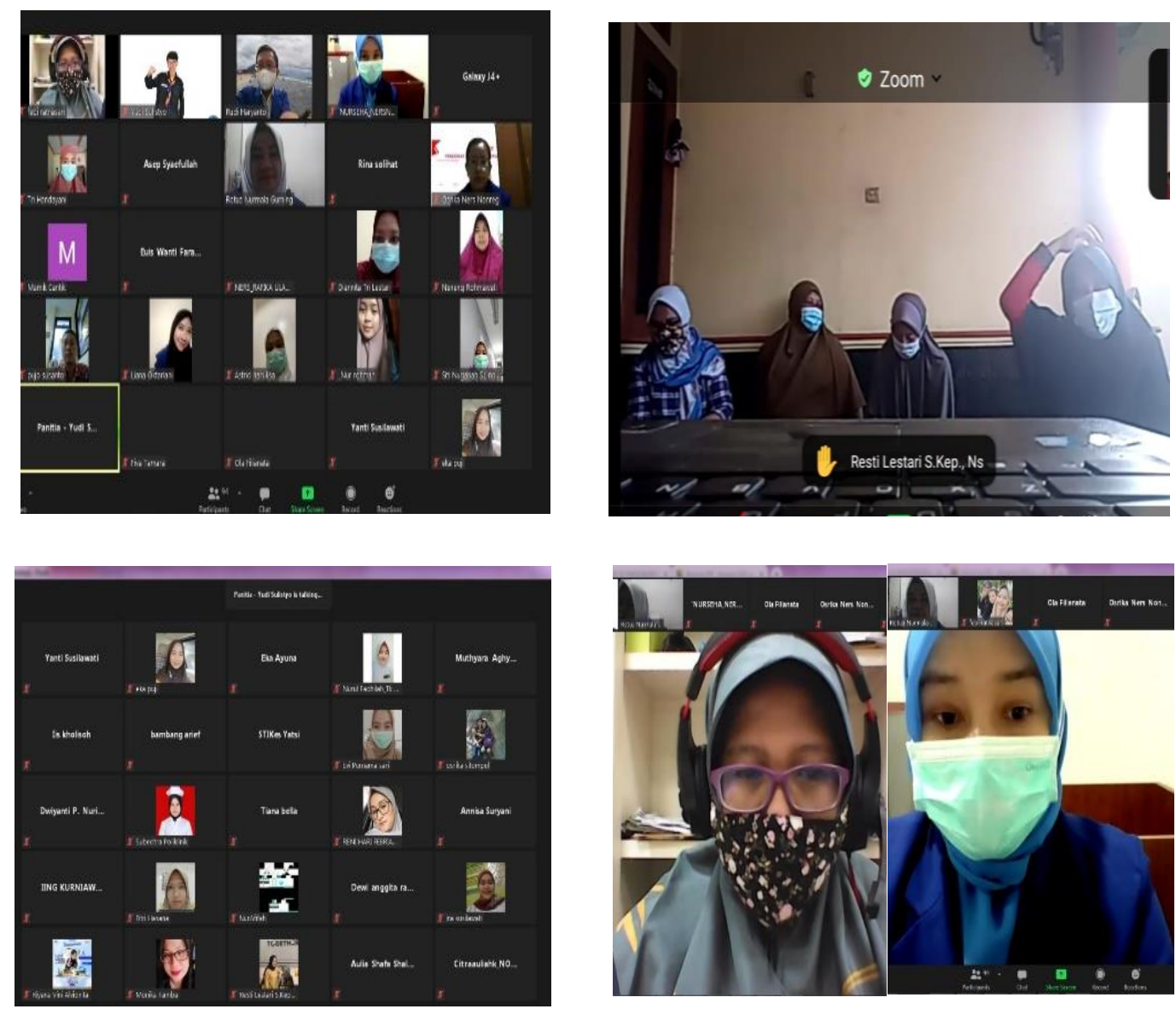

Gambar 4.8 Penyuluhan tentang pemberian ASI ekslusif secara daring 
Teknik dalam memberikan ASI yang benar kepada bayi diantaranya melalui pengaturan perlekatan dan posisi bayi secara baik dan benar. Bila tidak dilakukan dengan teknik yang benar akan berdampak terhadap payudara ibu diantaranya putting susu lecet, payudara bengkak dan ASI tidak mampu keluar dengan maksimal yang pada akhirnya dapat mempengaruhi produksi ASI dan mempengaruhi keberhasilan ibu dalam memberikan ASI ekslusif (Subekti, 2019).

Kuantitas dan kualitas ASI juga dipengaruhi oleh pemenuhan nutrisi yang cukup, dimana dengan nutrisi cukup akan meningkatkan kondisi fisik ibu, fisik yang baik akan meningkatkan kondisi psikis ibu, sehingga kondisi fisik dan psikis ibu sebagai faktor yang menentukan keberhasilan pemberian ASI (Rimawati, Melda, \& Nurwijayanti, 2018). Meningkatkan kenyamanan ibu menyusui dan meningkatkan produksi ASI dapat dilakukan dengan pijat oksitoksin (Maita, 2016). Pemijatan tersebut dilakukan dibelakang punggung dan dapat meningkatkan hormon oksitoksin atau hormon kasih sayang yang mampu meningkatkan pemikiran positif pada ibu. Dengan pemijatan oksitoksin membuat ibu lebih relax karena pemijatan dibagian punggung merangsang banyak titik saraf dan merangsang pengeluaran oksitoksin dengan cepat. Pemijatan yang dilakukan secara teratur pada ibu postpartum $2 x$ sehari selama 2-3 menit akan meningkatkan produksi ASI (Wulandari, Menik, \& Khusnul, 2018).

Kegiatan penyuluhan kesehatan ini terdiri dari pengisian soal pre-test, penyampaian materi mengenai manajemen laktasi dan manfaat ASI ekslusif, demonstrasi cara menyusui yang baik dan benar, demonstrasi Teknik pijat oksitosin, dilanjutkan sesi tanya jawab dan diakhiri dengan pengisian soal posttest. Peserta mengikuti pemateri mulai mendengarkan presentasi, menyaksikan demonstrasi dan mengikuti sesi tanya jawab. Peserta yang hadir dalam penyuluhan tampak sangat antusias mengikuti penyuluhan dari awal sampai akhir. Pengetahuan peserta saat evaluasi diketahui meningkat.

\section{KESIMPULAN}

Kesimpulan dari uraian kegiatan pengabdian masyarakat tersebut antara lain dengan dilakukan penyuluhan maka terdapat peningkatan pengetahuan ibu-ibu tentang teknik menyusui bayi dengan benar yang awalnya hanya $48 \%$ naik menjadi $80 \%$ serta terdapat peningkatan pengetahuan ibu tentang cara meningkatkan produksi ASI dari 50\% menjadi $90 \%$.

\section{DAFTAR PUSTAKA}

Agustina, R., Prabandari, Y. S., \& Sudargo, T. (2020). Hambatan pemberian ASI ekslusif pada ibu bekerja: teori ekologi sosial. Jurnal Gizi Klinik Indonesia, 17(2), 64. https://doi.org/10.22146/ijcn.50155

Anggraini, Y., Sari, R. P., \& Utami, U. (2020). Determinan Keberhasilan Pemberian ASI Eksklusif pada Ibu Balita di Posyandu Anggrek Trowangsan Colomadu. Jurnal IImiah Maternal, IV(10), 57-63.

Kementerian Kesehatan RI. (2019). STUDI STATUS GIZI BALITA DI INDONESIA TAHUN 2019.

Kementerian Kesehatan RI. (2020). Profil Kesehatan Indonesia Tahun 2019. https://doi.org/10.5005/jp/books/11257_5 
Maita, L. (2016). PENGARUH PIJAT OKSITOSIN TERHADAP PRODUKSI ASI. Jurnal Penelitian Kesehatan Suara Forikes, VII, 173-175.

Martin, C. R., Ling, P. R., \& Blackburn, G. L. (2016). Review of infant feeding: Key features of breast milk and infant formula. Nutrients, 8(5), 1-11. https://doi.org/10.3390/nu8050279

Mustafa, D., \& Ibrahim. (2019). Hubungan Pengetahuan dan Sikap Ibu dengan Pemberian ASI eksklusif di Wilayah Kerja Puskesmas Meral Kabupaten Karimun Kabupaten Kepulauan Riau. Kebidanan, 09(02).

Novitasari, Y., Mawati, E. D., \& Rachmania, W. (2019). Faktor-Faktor Yang Berhubungan Dengan Perilaku Pemberian Asi Ekslusif Di Puskesmas Tegal Gundil Kota Bogor Jawa Barat Tahun 2018. Promotor, 2(4), 324. https://doi.org/10.32832/pro.v2i4.2246

Rimawati, Melda, B., \& Nurwijayanti. (2018). Kondisi Psikologis Dan Fisik Dalam Pemberian Asi Ekslusif Pada Ibu Bekerja Di Stikes Rs. Baptis Kediri. Jurnal Penelitian Keperawatan, 4(1). https: / /doi.org/10.32660/jurnal.v4i1.316

Risnayati, Sudirman, \& Rosnawati. (2018). Faktor-Faktor Yang Berhubungan Dengan Pemberian Asi Eksklusif Pada Bayi Di Wilayah Kerja Puskesmas Siniu Kabupaten Parigi Moutong. Kolaboratif SAINS, 1(1). https: //doi.org/10.31934/jom.v1i1.353

Sampe, A., Toban, R. C., \& Madi, M. A. (2020). Hubungan Pemberian Asi Eksklusif Dengan Kejadian Stunting Pada Balita. Jurnal Ilmiah Kesehatan Sandi Husada, 11(1). https://doi.org/10.24269/hsj.v4i1.409

Subekti, R. (2019). Teknik Menyusui yang Benar di Desa Wanaraja, Kecamatan Wanayasa Kabupaten Banjarnegara. Jurnal Penelitian Dan Pengabdian Kepada Masyarakat UNSIQ, 6(1), 45-49. https: / / doi.org/10.32699/ppkm.v6i1.550

WHO. (2019). Levels and trends in child malnutrition (UNICEF / WHO / World Bank Group Joint Child Malnutrition Estimates). Asia-Pacific Population Journal, 1-16.

Wulandari, P., Menik, K., \& Khusnul, A. (2018). Peningkatan Produksi ASI Ibu Post Partum melalui Tindakan Pijat Oksitosin. Jurnal Ilmiah Keperawatan Indonesia [JIKI], 2(1), 33. https: //doi.org/10.31000/jiki.v2i1.1001 